\title{
Development of cobalt ferrite powder preparation employing the sol-gel technique and its structural characterisation
}

\author{
M. Sajjia ${ }^{1 \mathrm{a}}$, , M. Oubaha ${ }^{2}$, T. Prescott ${ }^{1}$, and A.G. Olabi ${ }^{1}$ \\ 1 School of Mechanical and Manufacturing Engineering, Dublin City University, Glasnevin, Dublin 9, \\ Ireland. \\ 2 Optical Sensor Laboratory, National Centre for Sensor Research, Dublin City University, Glasnevin, Dublin \\ 9, Ireland.
}

\begin{abstract}
This work focuses on the development of a method to make nano cobalt ferrite powder using a solgel process. A particular emphasis is devoted to the understanding of the role of the chemical parameters involved in the solgel technique, and of the heat treatment on the structures and morphologies of the materials obtained. Several samples of cobalt ferrite powder were obtained by varying the initial parameters of the process in addition to the heat treatment temperature. Xray diffraction and scanning electron microscopy were used to identify the structure and morphology of samples demonstrating the influence of the initial parameters. DTA/TGA was carried out on one sample to identify important reaction temperatures during the heat treatment. The average particle size, as estimated for one sample by the full width at half maximum (FWHM) of the strongest Xray diffraction (XRD) peak, was found to be about $45 \mathrm{~nm}$. It has been found that the chelating agent and the crosslinker have a critical influence on the resultant structure, the particle size and the particle size distribution.
\end{abstract}

\section{Keywords}

sol-gel; cobalt ferrite nanoparticles; spinel structure; crosslinker; chelating agent.

\section{References}

1 C.N. Chinnasamy, M. Senoue, B. Jeyadevan, O. PeralesPerez, K. Shinoda, K. Tohji, J. Colloid. Interf. Sci. 263, 80 (2003)

2 L. Ai, J. Jiang, Curr. Appl. Phys. doi:10.1016/j.cap.2009.06.007

3 B.E. Kashevsky, V.E. Agabekov, S.B. Kashevsky, K.A. Kekalo, E.Y. Manina, I.V. Prokhorov, V.S. Ulashchik, Particuology. 6, 322 (2008)

a e-mail : sajjiam2@mail.dcu.ie

This is an Open Access article distributed under the terms of the Creative Commons Attribution-Noncommercial License 3.0, which permits unrestricted use, distribution, and reproduction in any noncommercial medium, provided the original work is properly cited. 